\title{
An Analysis of Learning Efficiency Affecting Factors in Open Education Learners
}

\author{
Pengju Lu ${ }^{1}$, Le $\mathrm{Luo}^{2}$ \\ ${ }^{1}$ Sichuan Radio and TV University, Chengdu, Sichuan, 610000, China \\ ${ }^{2}$ Sichuan Architectural Vocational and Technical College, Chengdu, \\ Sichuan, 610399, China
}

\begin{abstract}
This paper analyzes the factors that affect the learning efficiency of open education learners, provides the basic conditions of individual and related factors of open education learners, and provides scientific basis for the study and construction of open education learning mode. At last, we provide the focus and issues we need to analysis and deal with.

Keywords: analysis, learning efficiency, affecting factors, open education learners

\section{Introduction}

Self-regulated learning is the essence of open education, and learner autonomy learning efficiency is one of the important indexes to measure the quality of open education. To improve learners' autonomous learning efficiency is one of the ways to improve the quality of open education. At the same time, as the object of open education is adult learners, their time for learning is limited, and higher learning efficiency in open universities is also a common demand for adult learning. This paper explores the factors that influence the efficiency of learner autonomy in open education, and reveals how these factors affect the efficiency of learning in order to provide the basis information to improve the learners' autonomous learning efficiency in open education.
\end{abstract}




\section{The individual factors of autonomy learning efficiency for open education learner}

\subsection{Self-learning awareness}

Most of the learners have a more accurate understanding of the learning styles of open education, and recognize that open education is fundamentally different from ordinary higher education or online learning. But there are still many learners do not have an accurate understanding. In the interview, it is found that some learners think that the adult learners lack the ability of autonomous learning, the open universities should be the same as those in ordinary colleges and universities, and the learners can achieve systematic learning through centralized face-to-face counselling. The teaching mode of the open education is very different from the traditional classroom teaching. The teaching mode of the open education is centred on the students' autonomous learning. The learning is a conscious behaviour of the students. The teachers mainly play the role of a guide, a tutor and a helper. This difference makes many students can not adapt well, especially in the first semester after school performance was the most prominent. Most of the students have not changed from the traditional concept and habits of group teaching and reading textbooks. Many students are hoping to get detailed explanations and analyzes of teacher systems in full-time university classrooms, often without preparation for face-to-face lectures and lack of interaction between teachers and students. Although some students agree with the open education teaching model and learning mode, most of the learners still like to accept the knowledge through reading printed materials and teachers face to face to accept knowledge; some students in learning difficulties, like direct To the teacher or classmates to ask the learning method. Some students also prejudice the idea of self-regulated learning, and think that autonomous learning lacks guidance and can not guarantee the quality of learning.

Open education requirements reflect the individuality and differences, students in the learning process can be developed according to their own learning plan, choose to register learning courses. However, in practice, due to the learner's sense of autonomy is not strong, more passive learning, dependence is very strong, the phenomenon of serious, in the usual case with the level of students with professional learning programs and curriculum choices are the same. At the same time, because of the long-term separation of teachers and students and the contradiction between the students and the students, the lack of timely monitoring of students' learning process, the lack of self-study consciousness and the lack of time and energy. The efficiency of learning is greatly affected.

\subsection{Learning motivation}

Motivation is to generate and cause behaviour of internal causes, behaviour is motivated by activities. Therefore, the learners' learning motivation will have an impact on learners' learning behaviour, thus affecting the learners' learning outcomes. The external motivation of learners' learning is dominated by open 
education, and the proportion of students who are learning is low. The survey data also show that many students choose to open the university because of this teaching model suitable for serving staff, opposite to the rate of class teaching is not mandatory, you can not participate in face-to-face counselling; it is also part of the learners to learn just to get Under the domination of the utilitarian purpose, the learners often neglect the normal learning and attach importance to the final coaching and the final exam because they lack the motivation and pressure to learn, grow knowledge and renew knowledge. Although some students are also self-improvement, with strong internal motivation, but often because of work, family and learning problems, prone to relax learning, just pass the exam phenomenon. Therefore, learning is easy to become passive, coping, self-learning efficiency is difficult to guarantee.

\subsection{Independent learning ability}

Successful autonomous learners should have the following three aspects of learning ability: First, master the learning resource retrieval methods, especially through the use of information technology for efficient learning; the second is to have a high self-learning ability, Writing learning ability and self-reflection, evaluation, monitoring ability; third is to study time, content, schedule, environment, resources, scientific planning and effective management. But on the whole, undergraduates' learning ability is higher than that of college students. With the further enrichment of learning experience, self-learning ability is also objective to enhance the inevitable. This objectively creates the original knowledge base, the knowledge background and the learning ability of the open education learners, the knowledge base is weak, and the autonomous learning ability is not strong. Such as open education requires learners have the ability to use multimedia and computer networks, access to information through the network, analysis of information, integrated information processing capabilities, but also have a strong self-monitoring capabilities, with the ability to communicate with others, build The ability of their own knowledge structure, and the current lack of some students do not even have these capabilities, can not adapt to the open education of learning.

\section{The school factor analysis of autonomy learning efficiency for the open education learner}

\subsection{Learning process support services}

Open University is a combination of learning and teaching model. The class teacher to undertake the task of guiding students, the general guidance of students, such as the opening of this semester counselling surface teaching, assessment methods can still, but in the specific course of the guidance of professional courses, the class teacher can not do. In addition to classroom instructor-led class instructors, only online teaching resources involved in the tutorial content and 
students post, the teacher replies the way. Therefore, in the true sense of the guidance is lacking, or even invalid.

\subsection{Course learning resources support services}

As an important part of curriculum resources, most teaching materials do not get rid of the traditional academic standards, the content is still academic-oriented. This obvious academic standard with the teaching materials is not conducive to self-study. A variety of media materials in the same curriculum in the arrangement should be an organic combination of teaching functions on the complementary advantages. However, in practice, the curriculum resources at all levels of learning platform does not achieve effective convergence and complement each other, and some overlapping repetition of curriculum resources, some resources are not updated in time, and some classification of resources inconsistent. There is also a lack of efficient search and filtering capabilities for the course learning resources. In the face of massive information on the network, due to the lack of efficient search and retrieval capabilities, students are easily submerged by information, online learning only.

\subsection{Technical facilities support services}

The utilization rate of technical facilities is not high. With the technical facilities of the hardware conditions continue to improve, the utilization rate of the facilities did not stride to improve. The use of cloud classrooms, for example, the teaching is to achieve the role of two-way video, teacher-student interaction frequency and time are less. The construction of open digital library provides learners with abundant, convenient and free electronic reading materials, and has full functions of query and document download. However, due to the lack of publicity and guidance of the learning centres, coupled with learners lack of interest in reading, there are very few students access to online and download information, digital library is far from its due role.

At present, the open education also lacks the effective monitoring means to the student on-line study process and the on-line study completely becomes student's conscious behaviour. The vast majority of courses to carry out online teaching, online Q \& A, discussion and group activities, students have a track record of online learning time. But the current time for students to record online learning is limited to video resources, some courses can not be recorded without video resources, and other resources can see the download rate and click rate, as well as face to class rate of these are not fully with the students shape Test results linked. Students who do not participate in face-to-face teaching and online learning also lack certain disciplinary measures.

\subsection{Administrative support services}

Learners in learning the basic to timely access to the above information, but there are still the following questions: (1) the number of teachers and the size of the learners do not meet. The teacher-student ratio is the direct result of the number 
of teachers and the size of the learners and courses are not suited to the learners from the teacher's targeted help is very limited. (2) the examination system, focusing on final examinations, form a low proportion. There are unreasonable aspects of the examination system, the results of most of the courses focus on final examinations, form a low proportion of test results and shape to obtain a great deal of randomness. The monitoring of the learning process of the learners will be an urgent problem to be solved in the construction of the open system in the coming years. National Open University study network construction has been a breakthrough in the examination system and shape test increased the proportion of learning activities, the learning process to a certain degree of monitoring.

\section{Conclusion}

Autonomous learning is the essence of open education, and learner autonomy learning efficiency is one of the important indexes to measure the quality of open education. Improving the learners' autonomous learning efficiency is one of the best ways to improve the quality of open education. Therefore, this paper studies the factors that affect the learning efficiency of open education learners, hoping to improve the open education in many aspects, so that the learners of open education can obtain higher learning efficiency.

\section{Acknowledgements}

The Causes Analysis and the Countermeasures of the Learning Delay for Open Education Learners - Taking Sichuan as an Example (KTKYC2016012Q)

\section{References}

[1] Wang Hui. An Analysis of Factors Affecting Learners' Learning Efficiency in Open Education. Continuing Education Research, 55(12), pp.68-70, 2011

[2] Wen Jianxin. Research on improving the efficiency of online self-regulated learning in distance open education. Journal of Jiangxi Radio and Television University, 8 (5), pp.87- 91, 2013

[3] Zhou Wei. A Study on the Current Situation of Learning Support Service in Modern Distance Education, Chinese Distance Education, 12(10), pp. 18- 20, 2012

[4] Liu Zhenfang. Mobile learning is a new direction for the development of modern educational technology, China Education and Training, 9(6), pp.58-61, 2011

[5] Lu Wenyi. Kindergarten Teaching Art. Chongqing: Southwest China Normal University Press, pp.85-87, 2014 